\title{
Kryteria oceny w metodzie magnetycznej pamięci metalu
}

\section{Assessment criteria in the metal magnetic memory testing}

\section{Streszczenie}

W metodzie magnetycznej pamięci metalu MPM ocenę stopnia koncentracji naprężeń prowadzi się wykorzystując wartości gradientów składowych własnego magnetycznego pola rozproszenia WMPR. Aby ocenić stan tworzywa, lokalną, maksymalną wartość gradientu odnosi się do wartości średniej w elemencie i porównuje się ją z wartością graniczną. W artykule wykazano niepoprawność proponowanego w metodologii metody sposobu określenia kryteriów ilościowych - wartości granicznych, na podstawie własności wytrzymałościowych tworzywa. Stwierdzono, że przy opracowywaniu kryteriów oceny należy oprócz tworzywa elementu uwzględniać jego geometrię, wartości zewnętrznego pola magnetycznego, jak również orientację elementu w tym polu.
Abstract

In the metal magnetic memory (MMM) testing the assessment of the level of stress concentration is carried out using the values of the gradients of the residual magnetic field (RMF) components. In order to assess the state of the material, the local maximum gradient value is referred to the average value in the component and compared to the boundary value. It is shown that the way proposed in the testing methodology to determine the quantitative criteria - the boundary values - based on the mechanical properties of the material is incorrect. It is found that the component material itself is not the only factor that has to be taken into account while developing the assessment criteria. Its geometry, the values of the external magnetic field, together with the component orientation in this field, have to be considered as well.

\section{Wstęp}

Metoda magnetycznej pamięci metalu (MPM) jest pasywną metodą magnetyczną wykorzystującą własne magnetyczne pole rozproszenia (WMPR) badanego elementu [1, 2]. W latach 2008 i 2009 wydane zostały polskie normy dotyczące metody MPM [3]. PN ISO 24497-1 wprowadza system pojęć stosowanych w tej metodzie, PN ISO 24497-2 opisuje wymagania ogólne jej stosowania, a PN ISO 24497-3 kontrolę połączeń spawanych z wykorzystaniem MPM. Według zapisów tych norm, ocenę stopnia koncentracji naprężeń prowadzi się wykorzystując wartości gradientów składowych WMPR. Aby ocenić stan tworzywa, maksymalną wartość gradientu odnosi się, do wartości średniej w badanym obszarze, otrzymując tzw. indeks magnetyczny $\mathrm{m}$ zdolności deformacji materiału.

W PN ISO 24497-3 dotyczącej badań połączeń spawanych podane są wartości graniczne tego indeksu

Dr inż. Maciej Roskosz - Politechnika Śląska, Gliwice. w zależności od wymaganej jakości złącza. W [4] pokazano wyniki badań połączeń spawanych metodą MPM. Wykazano, że proponowana metodologia prowadzenia badań jest poprawna, szczególnie dla badań spoin na etapie eksploatacji. Natomiast ilościowe kryteria oceny są złe. Ich niepoprawność wynika z ich ogólności. Nie uwzględniają one rodzaju spoiny, jej tworzywa, warunków prowadzenia spawania i innych czynników, które mogą wpływać na WMPR spoiny i strefy wpływu ciepła.

Dla dowolnego elementu, badanego metodą MPM, w PN ISO 24497-2 mowa jest jedynie o „specjalnej procedurze" wyznaczania wartości dopuszczalnych indeksu magnetycznego zdolności deformacji materiału $\mathrm{m}_{\text {lim }}$. Nic więcej; $w$ normie nie podano $w$ jaki sposób i w jakich warunkach określać jego wartość. W pracy Dubowa i Własowa [5] występuje zależność na określenie wartość dopuszczalnej tego indeksu na podstawie właściwości wytrzymałościowych. W [6] stwierdzono, że w strefach koncentracji naprężeń rzeczywiście występują maksymalne wartości gradientów WMPR. Jednak wpływ obciążenia, wartości zewnętrznego pola magnetycznego lub położenia próbki w magnetycznym polu Ziemi na wartości gradientów jest znaczący. Stwierdzono wiele nieścisłości $w$ metodologii oceny stanu 
oraz wykazano, że wykorzystanie właściwości wytrzymałościowych tworzywa do wyznaczania wartości granicznej indeksu magnetycznego prowadzi do błędów w ocenie stanu tworzywa elementu $[6,7]$. llościowe kryteria oceny w metodologii metody MPM, oparte tylko na właściwościach wytrzymałościowych tworzywa, są nieprawidłowe.

Wykorzystanie WMPR jako sygnału diagnostycznego w wielu zastosowaniach sprawdza się bardzo dobrze, uzupełniając standardowe metody badań nieniszczących. Jednak określenie sposobu prowadzenia badań oraz kryteriów oceny następuje na drodze eksperymentu i/lub zbierania, analizy i syntezy da-

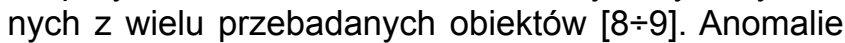
w rozkładzie WMPR elementu mogą być wynikiem występowania w nim nieciągłości, jak również lokalnych zmian właściwości magnetycznych i elektrycznych będących skutkiem różnych procesów zużycia. W dalszej części pracy zostaną przedstawione czynniki, które zdaniem autora mają wpływ na WMPR elementu i które powinno się uwzględniać przy opracowywaniu kryteriów oceny stanu tworzywa elementu.

\section{Czynniki wpływające na kryteria oceny w metodzie MPM}

Można przyjąć, że WMPR elementu jest wynikiem zachodzących oddziaływań pomiędzy tym elementem, jego obciążeniem a otoczeniem.

Element jest tutaj rozumiany jako artefakt o określonej geometrii wykonany z określonego tworzywa. Otoczenie to pole magnetyczne, w którym element się znajduje. Zagadnienia identyfikacji ziemskiego pola magnetycznego jako otoczenia elementu przedstawiono w [10, 11]. Na powierzchni elementu, przy określonej orientacji w danym otoczeniu, występuje unikatowy rozkład WMPR. Rozkład ten ulega zmianom w czasie „życia” elementu. Zakładając niezmienność otoczenia, zmiany te są skutkiem obciążeń eksploatacyjnych i zachodzących w elemencie procesów zużycia. Obserwacja i analiza tych zmian, połączona z oceną stopnia wytężenia i/lub stopnia zużycia (przez eksperyment lub modelowanie), umożliwia opracowanie ilościowych kryteriów oceny stanu technicznego elementu. Dotyczy to zarówno nieciągłości geometrycznych, które mogą wystąpić w elemencie, jak też fazy przed powstaniem makroskopowej nieciągłości. Wychwycenie procesów rozwoju nieciągłości w skali mikro i identyfikacja obszarów, w których procesy te zachodzą są szczególnie interesujące. Wynika to z tego, że standardowe metody badań nieniszczących zorientowane są na wykrywanie nieciągłości geometrycznych w skali makro, co nie zapewnia w wielu przypadkach wymaganej obecnie niezawodności eksploatacji.

W elemencie ferromagnetycznym, znajdującym się w polu magnetycznym, pod wpływem naprężeń zmienia się stopień namagnesowania. Zmiana namagnesowania ma składową odwracalną, zanikającą po odciążeniu, oraz składową stałą. Na skutek działania efektu magnetosprężystego, naprężenia mechaniczne wpływają na anizotropię energii domen magnetycznych, najczęściej powodując zmiany przenikalności. Kierunek tej anizotropii jest zależny od magnetostrykcji. Dla materiałów z dodatnią magnetostrykcją momenty magnetyczne dążą do ustawienia się równolegle do kierunku naprężenia rozciągającego, a prostopadle do ściskającego. W materiałach o ujemnej magnetostrykcji zachodzą zjawiska przeciwne - momenty magnetyczne dążą do ustawienia się prostopadle do kierunku naprężenia rozciągającego, a równolegle do ściskającego. Wpływ stanu wytężenia na rozkład WMPR elementu pokazano w pracach

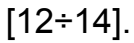

\section{Wpływ namagnesowania i geometrii elementu na WMPR}

\section{Teoria}

WMPR jest wynikiem jednoczesnego działania zewnętrznego pola magnetycznego $\mathbf{H}_{\mathrm{a}}$ oraz pola rozmagnesowania $\mathbf{H}_{d}$ związanego $\mathbf{z}$ namagnesowaniem obiektu M oraz jego geometrią. Pomijając wpływ zewnętrznego pola magnetycznego, w każdym punkcie w bliskim otoczeniu obiektu, wartość zmierzonego pola magnetycznego jest wypadkową oddziaływania rozkładu namagnesowania całego elementu. Poniższe rozważania, opracowane na podstawie [15], mają na celu przybliżenie istoty tego, czym jest WMPR mierzone w pobliżu obiektu ferromagnetycznego oraz co na WMPR wpływa.

Indukcja magnetyczna B wewnątrz namagnesowanego elementu wyraża się wzorem:

$$
B=\mu_{0}(H+M)
$$

gdzie: $\mu_{0}$ jest przenikalnością magnetyczną próżni.

Przy braku przepływu prądu elektrycznego równania magnetostatyczne Maxwella można zapisać w postaci

$$
\begin{aligned}
& \operatorname{div}(B)=\nabla \cdot B=0 \\
& \operatorname{rot}(H)=\nabla \times H=0
\end{aligned}
$$

Z równań $(1) \div(3)$ otrzymujemy

$$
\nabla \cdot H=\left\{\begin{array}{cc}
-\nabla \cdot M \text { wewnątrz ferromagnetyka } \\
0 \quad \text { na zewnątrz }
\end{array}\right.
$$

Ponieważ rotacja $\mathbf{H}$ jest równa zeru, można wprowadzić pojęcie skalarnego potencjału magnetycznego $\mathrm{V}$ spełniającego równanie rot grad $\mathbf{V}=\mathrm{V} \times \nabla \mathrm{V}=0$. Otrzymuje się wówczas:

$$
H=-\operatorname{grad} V=-\nabla V
$$




\section{Zależność (4) można zapisać jako}

$$
\nabla^{2} \cdot V= \begin{cases}-\nabla \cdot M & \text { wewnątrz ferromagnetyka } \\ 0 & \text { na zewnątrz }\end{cases}
$$

Na granicy między dwoma środowiskami o różnych przenikalnościach magnetycznych $\mu_{1}$ i $\mu_{2}$ składowa styczna wektora natężenia pola magnetycznego $\mathrm{H}$ jest ciągła oraz składowa normalna wektora indukcji magnetycznej B jest ciągła. Stąd na powierzchni ferromagnetyka:

$$
\begin{gathered}
V_{\text {wew }}=V_{\text {zew }} \\
\frac{\partial V_{\text {wew }}}{\partial \mathrm{n}}-\frac{\partial \mathrm{V}_{\text {zew }}}{\partial \mathrm{n}}=\mathbf{M} \cdot \mathbf{n}
\end{gathered}
$$

gdzie: $\boldsymbol{\eta}$ jednostkowy wektor normalny do powierzchni ferromagnetyka, $V_{\text {wew }}$ i $V_{z e w}$ skalarny potencjał magnetyczny, odpowiednio wewnątrz i na zewnątrz ferromagnetyka.

Dla danego namagnesowania M można określić potencjał wewnątrz i na zewnątrz ferromagnetyka, rozwiązując równania $(6) \div(8)$. Rozwiązanie dla wektora położenia r ma postać:

$$
V(\mathbf{r})=\mathbf{V}_{\mathrm{a}}(\mathbf{r})+\mathbf{V}_{\mathrm{d}}(\mathbf{r})
$$

gdzie $\mathbf{V}_{\mathrm{a}}(\mathbf{r})$ to skalarny potencjał magnetyczny wywołany zewnętrznym polem magnetycznym $\mathbf{H}_{\mathrm{a}}$, a $\mathrm{V}_{\mathrm{d}}(\mathbf{r})$ to potencjał wywołany namagnesowaniem ferromagnetyka $\mathbf{M}$. $\mathbf{V}_{d}(\mathbf{r})$ opisuje równanie:

$$
V_{d}(\boldsymbol{r})=\frac{1}{4 \pi}\left(\int_{\forall} \frac{-\nabla \cdot \mathbf{M}(\mathbf{s})}{|\mathbf{r}-\mathbf{s}|} d \forall+\int_{S} \frac{\mathbf{n} \cdot \mathbf{M}(\mathbf{s})}{|\mathbf{r}-\mathbf{s}|} d S\right)
$$

gdzie $\forall$ jest objętością, $S$ jest polem powierzchni ferromagnetyka, a $\mathbf{s}$ jest wektorem położenia dowolnego punktu wewnątrz lub na powierzchni ferromagnetyka.

Korzystając ze wzoru (5), natężenie pola magnetycznego w pobliżu obiektu ferromagnetycznego można opisać zależnością:

$$
H(r)=H_{a}(r)+H_{d}(r)
$$

gdzie $\mathbf{H}_{\mathrm{a}}$ jest natężeniem zewnętrznego pola magnetycznego, a $\mathbf{H}_{\mathrm{d}}$ jest natężeniem pola magnetycznego wywołanego namagnesowaniem ferromagnetyka. $\mathbf{H}_{d}$ jest nazywane polem rozmagnesowania $\mathrm{i}$ opisuje je równanie:

$$
\mathbf{H}_{d}(\boldsymbol{r})=\frac{1}{4 \pi} \int_{\forall} \frac{-\nabla \cdot \mathbf{M}(\mathbf{s})}{|\mathbf{r}-\mathbf{s}|^{3}}(\mathbf{r}-\mathbf{s}) d \forall(\boldsymbol{s})+\frac{1}{4 \pi} \int_{s} \frac{\mathbf{n} \cdot \mathbf{M}(\mathbf{s})}{|\mathbf{r}-\mathbf{s}|^{3}}(\mathbf{r}-\mathbf{s}) d S(s)(
$$

Dany rozkład namagnesowania $\mathbf{M}(\mathbf{s})$ skutkuje unikatowym rozkładem natężenia pola magnetycznego $\mathbf{H}(\mathbf{r})$.

\section{Eksperyment}

Celem eksperymentu było określenie wpływu kształtu próbki, przy znanym poziomie naprężeń resztkowych, na wartości gradientów. Badano próbki płytowe wykonane ze stali $16 \mathrm{Mo} 3$ o dwóch różnych geometriach A i B, które pokazano na rysunkach 1 . Próbki obciążono siłą rozciągającą, która spowodowała wystąpienie w osłabionych przekrojach próbek naprężenia nominalnego równego $450 \mathrm{MPa}$. Próbki odciążono i przeprowadzono pomiary WMPR.

Mierzono dwie składowe WMPR na powierzchni próbek wzdłuż osi symetrii na linii o długości $200 \mathrm{~mm}$ :

- $\mathrm{H}_{\mathrm{TY}}$ - składowa styczna mierzona w kierunku równoległym do kierunku zadawanego obciążenia,

- $\mathrm{H}_{\mathrm{N}, \mathrm{Z}}$ - składowa normalna.

Obciążenie wywołało nierównomierne odkształcenia plastyczne w strefach karbu, a wskutek tego

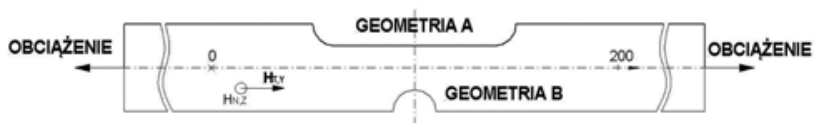

Rys. 1. Próbki do badań

Fig. 1. Sample for tests

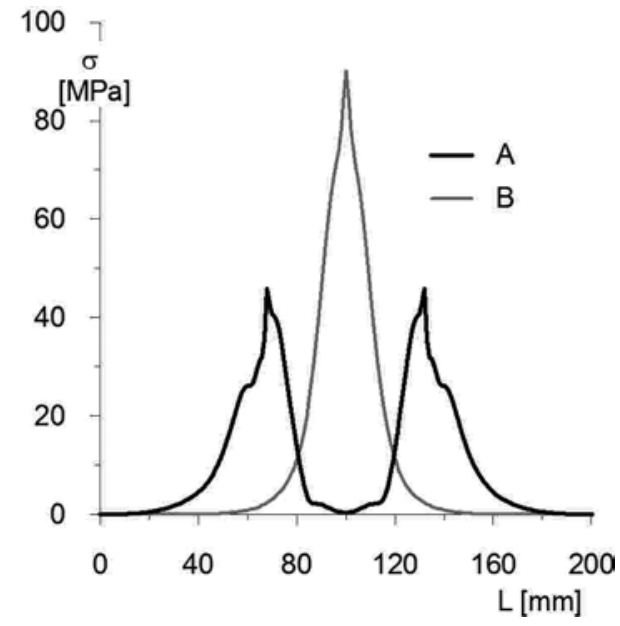

Rys. 2. Obliczone rozkłady zredukowanych naprężeń resztkowych w próbkach A i B

Fig. 2. The calculated distribution of the reduced residual stress in the samples $A$ and $B$

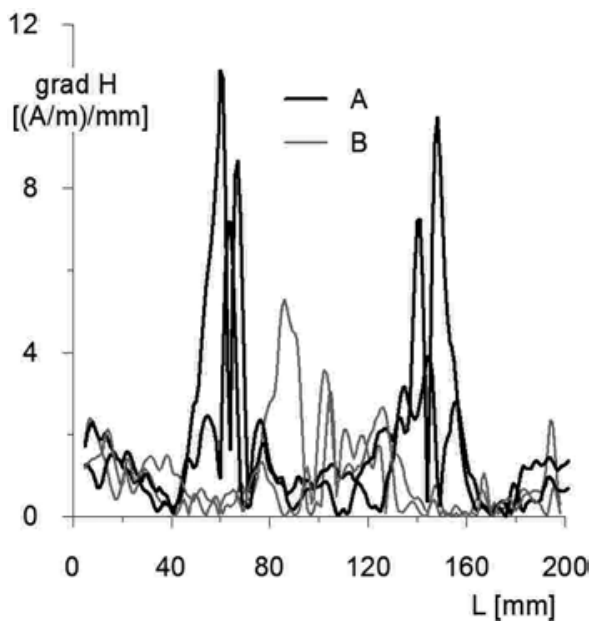

Rys. 3. Rozkłady gradientów składowych WMPR w próbkach A i B Fig. 3. WMPR distributions gradient components in the samples $A$ and $\mathrm{B}$ 
pojawienie się w tych miejscach naprężeń resztkowych. Rozkład tych naprężeń w próbkach modelowano przy zastosowaniu MES. Sposób prowadzenia obliczeń opisano $w[9,12]$.

Rozkłady zredukowanych naprężeń resztkowych pokazano na rysunku 2. W próbce o geometrii B ich poziom jest ok. 2 razy większy niż w próbce A. Wyznaczone na podstawie pomiarów wartości gradientów składowych WMPR pokazano na rysunku 3. Wartości gradientów w próbce o geometrii A są ok. 2 razy większe niż w próbce $B$. Wyższym wartościom naprężeń w próbce $B$ nie odpowiadają wyższe wartości gradientów. Wpływ geometrii elementu na wartości gradientów jest bardzo znaczny. Ilościowe kryteria oceny stanu tworzywa elementu muszą uwzględniać jego cechy geometryczne.

\section{Podsumowanie}

Przeprowadzono analizę kryteriów oceny stanu tworzywa w metodzie MPM. Wykazano niepoprawność proponowanego w metodologii sposobu określenia kryteriów ilościowych - wartości granicznych, na podstawie właściwości wytrzymałościowych tworzywa. Stwierdzono, że przy opracowywaniu kryteriów oceny należy oprócz tworzywa elementu uwzględniać jego geometrię, wartości zewnętrznego pola magnetycznego, jak również orientację elementu w tym polu.

\section{Literatura}

[1] Deputat J.: Podstawy metody magnetycznej pamięci metalu. Dozór Techniczny 5/2002, s. 97-105.

[2] Dubow A.A.: Principial features of metal magnetic memory method and inspection tools as compared to known magnetic NDT methods. WCNDT 2004, Montreal Canada, http://www. ndt.net/article/wcndt2004/papers/359.ntm

[3] PN-ISO 24497-1, 2, 3 Badania nieniszczące - Magnetyczna pamięć metalu - Część 1: Słownictwo, Część 2: Wymagania ogólne, Część 3: Kontrola złączy spawanych.

[4] Roskosz M.: Metal magnetic memory testing of welded joints of ferritic and austenitic steels, NDT\&E International 44 (2011), 305-310.

[5] Własow W.T., Dubow A.A: Ocena poziomu naprężeń w strefach ich koncentracji według metody magnetycznej pamięci metalu. XIV Seminarium Nieniszczące Badania Materiałów, Zakopane 2008.

[6] Roskosz M., Bieniek M.: Analysis of the methodology of the assessment of the technical state of a component in the method of metal magnetic memory testing, Proceedings Defektoskopie 2010/ NDE for Safety, s. 229-236.

[7] Augustyniak M.: Praktyczne ograniczenia stosowalności metody magnetycznej pamięci metali $w$ diagnostyce instalacji energetycznych, 4 Konferencja Naukowo-Techniczna „Diagnostyka Materiałów i Urządzeń Technicznych”, Gdańsk 2012.

[8] Roskosz M.: Possibilities of the Application of the Metal Magnetic Memory Method to the Analysis of Gear Durability. 9th European Conference on Non-Destructive Testing ECNDT Berlin 2006, Abstracts Part 2, s. 85.

\section{Podziękowanie}

Przedstawione w artykule wyniki zostały uzyskane w badaniach współfinansowanych przez Narodowe Centrum Badań i Rozwoju w ramach umowy SP/E/1/67484/10 - Strategiczny Program Badawczy - Zaawansowane technologie pozyskiwania energii: Opracowanie technologii dla wysokosprawnych „zero-emisyjnych” bloków węglowych zintegrowanych z wychwytem $\mathrm{CO}_{2}$ ze spalin.
[9] Roskosz M., Bieniek M.: Evaluation of residual stress in ferromagnetic steels based on residual magnetic field measurements NDT\&E International 45 (2012) s. 55-62.

[10] Witoś M., Roskosz M.: Metal Magnetic Memory in Material Fatigue Analysis Part I - The Earth's magnetic field, JSAEM Studies in Applied Electromagnetics and Mechanics, Vol. 14 Applied Electromagnetics and Mechanics, eds. G. Rubinacci, A. Tamburrino, F. Villone, T. Takagi, Napoli 2011 s. 287-288.

[11] Witoś M.: The reference signal of geomagnetic field for MMM expert systems, Key Engineering Materials. V. 18, 2012, s. 384-395.

[12] Roskosz M., Rusin A., Bieniek M.: Analysis of relationships between residual magnetic field and residual stress, Meccanica 2012, DOI 10.1007/s11012-012-9582-x.

[13] Gontarz S., Radkowski S.: Impact of Various Factors on Relationships Between Stress and Eigen Magnetic Field in a Steel Specimen, IEEE Transactions on Magnetics, Vol. 48, No. 3, March 2012

[14] Roskosz M., Gawrilenko P.: Analysis of changes in residual magnetic field in loaded notched samples, NDT\&E International 41 (2008), s. 570-576.

[15] Sushant M. Dutta, Fathi H. Ghorbel Roderick K. Stanley: Dipole modeling of magnetic flux leakage. IEEE Transactions On Magnetics 45 (2009) s. 1959-1965. 